\title{
DETERMINATION OF AEROSOL STRONG ACIDITY LOSSES DUE TO INTERACTIONS OF COLLECTED PARTICLES: RESULTS FROM LABORATORY AND FIELD STUDIES
}

\author{
Petros Koutrakis, Kimberly M. Thompson, Jack M. Wolfson-and \\ JOHN D. SPENGLER \\ Harvard University, School of Public Health, 665 Huntington Avenue, Boston, MA 02115, U.S.A. \\ Gerald J. KeELer \\ University of Michigan, School of Public Health, Ann Arbor, MI 48109, U.S.A. \\ and \\ James L. SLATER \\ University of Steubenville, Steubenville, OH 43952, U.S.A. \\ (First received 2 April 1991 and in final form 30 July 1991)

\begin{abstract}
Existing methods of measuring atmospheric aerosol strong acidity adequately prevent neutralization of fine-particle acidity by removing coarse alkaline particles and gaseous ammonia from air samples. However, these techniques do not consider particle interactions on the collection medium; therefore, they may still underestimate the actual aerosol acidity. Assessment of acid neutralization due to such interactions is made possible using annular denuder technology in conjunction with a newly designed filter pack. The amount of sulfate-related acidity neutralized by the collected ammonium nitrate (and possibly ammonium chloride and organic acid ammonium salts) is determined. Laboratory data suggest that large fractions of sulfate-related aerosol acidity are neutralized by ammonium nitrate particles during collection on filter media. Field data from the Harvard Acid Aerosol Health Effects Study also suggest that ammonium nitrate and possibly other ammonium salts, such as ammonium chloride, neutralize collected acid aerosols. For low-acid aerosol concentrations, the correction factor is significant; whereas, for high-acid concentrations, correction is negligible.
\end{abstract}

Key word index: Aerosol acidity, sulfuric acid, ammonium nitrate, acid neutralization, annular denuder, filter pack particle interactions.

\section{INTRODUCTION}

Acidic ambient sulfate aerosols can be formed through homogeneous gas or aqueous phase reactions as well as through heterogeneous reactions on particle surfaces. A number of gas-particle reactions occur among the strongly acidic particles and atmospheric gases. Among these, the neutralization reaction with ammonia is the most important from the perspective of atmospheric acidity.

Depending upon the availability of ambient ammonia, acid aerosol sulfates may be partially or totally neutralized. Furthermore, depending on the acid aerosol content and ambient relative humidity, the partially or totally neutralized atmospheric sulfates remain in the liquid phase or change to the solid phase. It is also possible that acidic particles contain both phases, where the partition coefficient is given by the phase diagram of the system: $\mathrm{H}_{2} \mathrm{O}-\left(\mathrm{NH}_{4}\right)_{2} \mathrm{SO}_{4}-$ $\mathrm{H}_{2} \mathrm{SO}_{4}$ (Tang et al., 1978). The liquid phase is an aqueous solution of $\mathrm{NH}_{4}^{+}, \mathrm{H}^{+}, \mathrm{SO}_{4}^{2-}$ and $\mathrm{HSO}_{4}^{-}$ions and possibly undissociated $\mathrm{H}_{2} \mathrm{SO}_{4}$, if the solution is strongly acidic. The solid phase consists of pure sulfate salts, such as $\left(\mathrm{NH}_{4}\right)_{2} \mathrm{SO}_{4}, \quad\left(\mathrm{NH}_{4}\right)_{3} \mathrm{H}\left(\mathrm{SO}_{4}\right)_{2}$, $\mathrm{NH}_{4} \mathrm{HSO}_{4}$ or sulfate salt mixtures, such as $\left(\mathrm{NH}_{4}\right)_{2} \mathrm{SO}_{4}$ plus $\left(\mathrm{NH}_{4}\right)_{3} \mathrm{H}\left(\mathrm{SO}_{4}\right)_{2}$ or $\left(\mathrm{NH}_{4}\right)_{3} \mathrm{H}\left(\mathrm{SO}_{4}\right)_{2}$ plus $\mathrm{NH}_{4} \mathrm{HSO}_{4}$. The composition of the solid phase is also predicted by the sulfate phase diagram.

Ammonia vapor pressure is considerably lower above acid aerosol sulfates than it is over ammonium nitrate particles. The ammonium nitrate aerosol dissociation constant, $\mathrm{K}\left(\mathrm{NH}_{4} \mathrm{NO}_{3}\right)=\mathrm{P}\left(\mathrm{HNO}_{3}\right) \cdot \mathbf{P}\left(\mathrm{NH}_{3}\right)$, depends on temperature and relative humidity (Tang, 1980; Stelson and Seinfeld, 1982). Assuming that there is no mechanism preventing the neutralization of acid aerosols by ammonia, the presence of acidic particles in ambient air implies that no ammonium nitrate exists simultaneously. For relative humidities below $\approx \mathbf{9 8 \%}$, all nitric acid exists in the gas phase. Although ammonium nitrate and acid sulfate particles do not coexist in the sample air, they may be present at different times in a sampling period. Consequently, ammonium nitrate and acidic sulfate may be collected on the same multihour integrated sample.

The main objective of this paper is to examine losses of aerosol acidity on filter media during sampling due 
to interaction with ammonium nitrate. The paper focuses on the interactions between sulfate and nitrate particles because they are two of the most abundant aerosol species under typical atmospheres. Results from both laboratory and field studies are presented and discussed.

\section{SAMPLING AND ANALYSIS}

The Harvard/EPA Annular Denuder System (HEADS), designed for the sampling of atmospheric aerosols and gases, is presently being used to study health effects of acid aerosols on North American children. As depicted in Fig. 1, the sampler consists of a glass impactor, a series of annular diffusion denuders, and a filter pack. The glass impactor removes coarse particles, $d_{\mathrm{a}} \geqslant 2.1 \mu \mathrm{m}$, from the $10 \ell \mathrm{min}^{-1}$ air sample and allows gases and fine particles to pass into the annular denuders and filter pack components (Koutrakis et al., 1990). The first $\left(\mathrm{Na}_{2} \mathrm{CO}_{3}\right.$-coated) annular denuder (D1) quantitatively collects acidic gases, such as $\mathrm{HNO}_{3}, \mathrm{HONO}, \mathrm{SO}_{2}, \mathrm{HCl}, \mathrm{HCOOH}$ and $\mathrm{CH}_{3} \mathrm{COOH}$ (Possanzini et al., 1983). The second (citric acid-coated) denuder (D2) collects ammonia and protects the acid aerosols collected downstream on the Teflon filter from neutralization. Laboratory and field tests of the denuder collection efficiencies and capacities for $\mathrm{HNO}_{3}, \mathrm{HONO}, \mathrm{SO}_{2}$ and $\mathrm{NH}_{3}$ are described elsewhere (Koutrakis et al., 1988a; Brauer et al., 1989).

A filter pack containing three filters follows the series of annular denuders. The first filter (F1) is a Teflon membrane used to collect fine particles. The second

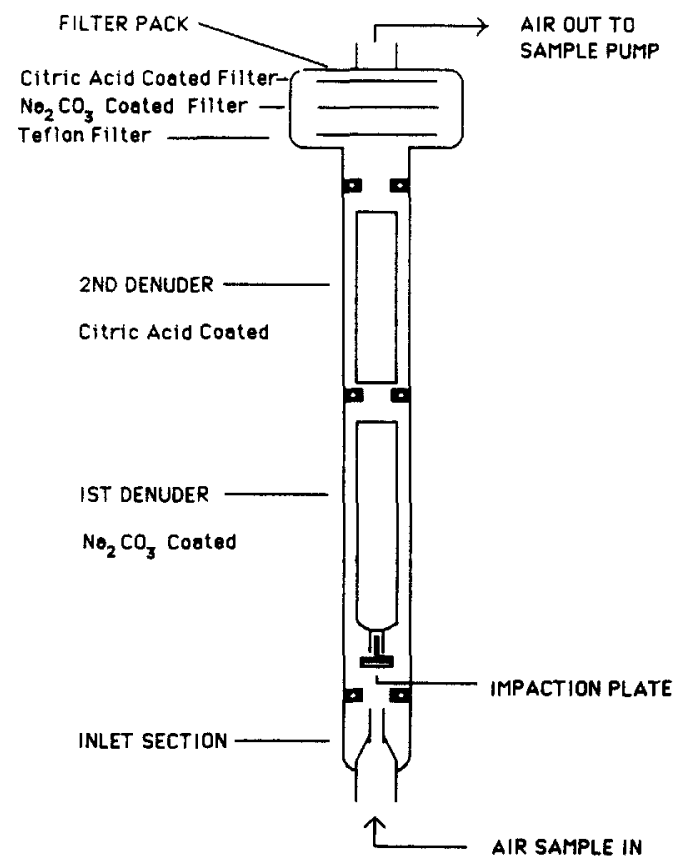

Fig. 1. Schematic of the Harvard/EPA Annular Denuder System (HEADS). filter (F2) is a $\mathrm{Na}_{2} \mathrm{CO}_{3}$-coated glass-fiber filter used to trap $\mathrm{HNO}_{3}$. The $\mathrm{HNO}_{3}$ originates from two sources; (i) the dissociation of $\mathrm{NH}_{4} \mathrm{NO}_{3}$ collected on the Teflon filter (F1) given by Equation (1), and (ii) the displacement of the sulfate related hydrogen ion by ammonium nitrate (Equation 2):

$$
\begin{aligned}
& \mathrm{NH}_{4} \mathrm{NO}_{3}(\mathrm{p}) \rightarrow \mathrm{NH}_{3}(\mathrm{~g})+\mathrm{HNO}_{3}(\mathrm{~g}) \\
& \mathrm{H}_{2} \mathrm{SO}_{4}, \mathrm{NH}_{4} \mathrm{HSO}_{4},\left(\mathrm{NH}_{4}\right)_{3} \mathrm{H}\left(\mathrm{SO}_{4}\right)_{2}(\mathrm{p}) \\
& \quad+\mathrm{NH}_{4} \mathrm{NO}_{3}(\mathrm{p}) \rightarrow\left(\mathrm{NH}_{4}\right)_{2} \mathrm{SO}_{4}(\mathrm{p})+\mathrm{HNO}_{3}(\mathrm{~g}) .
\end{aligned}
$$

The last component of the three-stage filter pack is a citric acid-coated glass-fiber filter (F4) used to trap ammonia originating from the dissociation of $\mathrm{NH}_{4} \mathrm{NO}_{3}$ collected on the Teflon filter (Equation 1).

This filter pack is a modification of a previous design. According to the original filter pack design, two $\mathrm{Na}_{2} \mathrm{CO}_{3}$-coated glass-fiber filters (F2 and $\mathrm{F} 3$ ) are used to allow for correction of artifact nitrogen oxides on the filter medium (Slater et al., 1989). This original design assumes that the artifact reactions of ambient nitrogen oxides occurring on the second $\mathrm{Na}_{2} \mathrm{CO}_{3}$-coated glassfiber filter (F3) are equivalent to those occurring on the first $\mathrm{Na}_{2} \mathrm{CO}_{3}$-coated glass-fiber filter (F2). Therefore, the nitrate and nitrite concentrations of the first filter (F2) are corrected by subtracting the nitrate and nitrite concentrations on the second filter (F3). However, an analysis of the first-year data of Harvard Acid Aerosol Health Effects Study suggested that this correction is minimal (less than $8 \%$ difference in the arithmetic means of $\mathrm{H}^{+}$(total), defined in Equation 3): thus, only one $\mathrm{Na}_{2} \mathrm{CO}_{3}$-coated filter (F2) is necessary for nitrate and nitrite collection.

After sampling, the denuders are extracted using deionized distilled water. The aqueous extract from the $\mathrm{Na}_{2} \mathrm{CO}_{3}$-coated denuder is analysed by ion chromatography coupled with a conductivity detector for $\mathrm{SO}_{4}^{2-}$, $\mathrm{NO}_{3}^{-}$and $\mathrm{NO}_{2}^{-}$to determine $\mathrm{SO}_{2}, \mathrm{HNO}_{3}$ and $\mathrm{HONO}$ concentrations, respectively. The aqueous extract from the citric acid-coated denuder is analysed by ion chromatography for $\mathrm{NH}_{4}^{+}$to determine the $\mathrm{NH}_{3}$ concentration.

All three of the filters in the filter pack are also extracted using deionized distilled water. One aliquot of the extracted solution from the Teflon membrane filter (F1) is analysed by ion chromatography to determine $\mathrm{SO}_{4}^{2-}, \mathrm{NO}_{3}^{-}, \mathrm{NO}_{2}^{-}$and $\mathrm{NH}_{4}^{+}$particulate concentrations. Another aliquot of the extracted solution from the Teflon membrane filter (F1) is analysed by a $\mathrm{pH}$ meter with a semi-microelectrode to determine aerosol strong acidity (Koutrakis et al., 1988b). The extracts from the $\mathrm{Na}_{2} \mathrm{CO}_{3}$-and the citric acid-coated glass-fiber filters (F2 and F4) are analysed using ion chromatography for $\mathrm{NO}_{3}^{-}$and $\mathrm{NO}_{2}^{-}$and $\mathrm{NH}_{4}^{+}$, respectively. The apparent aerosol strong acidity measurement for the Teflon filter (F1) (measured by the $\mathrm{pH}$-meter) is corrected using the ion chromatography results by adding the moles of nitrate measured on the $\mathrm{Na}_{2} \mathrm{CO}_{3}$-coated glass-fiber filter (F2) and subtracting the moles of 
ammonium measured on the citric acid-coated filter (F4) (Slater et al., 1989). This is demonstrated by Equations (3) and (4), where all concentrations are in moles per cubic meter. Nitrite does not appear in these equations because it is negligible:

$$
\mathrm{H}^{+}(\text {total })=\mathrm{H}^{+}(\mathrm{F} 1)+\mathrm{H}^{+}(\text {correction }),
$$

where

$$
\mathrm{H}^{+}(\text {correction })=\mathrm{NO}_{3}^{-}(\mathrm{F} 2)-\mathrm{NH}_{4}^{+}(\mathrm{F} 4) .
$$

\section{LABORATORY TESTS}

The interaction of $\mathrm{NH}_{4} \mathrm{NO}_{3}$ and acid aerosol sulfates on Teflon membrane filters during sampling was studied in a series of laboratory experiments. For these tests, an aerosol generation system (described by Brauer et al., 1989) was used to deposit pure $\mathrm{NH}_{4} \mathrm{NO}_{3}$ and/or $\mathrm{H}_{2} \mathrm{SO}_{4}$ aqueous droplets on the Teflon membrane filters. The aerosol generation system, depicted in Fig. 2, includes an air-scrubbing system, a dilution system, a humidity controller and a baffled-jet nebulizer. The $\mathrm{H}_{2} \mathrm{SO}_{4}$ and $\mathrm{NH}_{4} \mathrm{NO}_{3}$ aerosols are produced using aqueous $\mathrm{H}_{2} \mathrm{SO}_{4}$ and $\mathrm{NH}_{4} \mathrm{NO}_{3}$ solutions, respectively. To minimize contamination, separate nebulizers, Teflon lines and mixing vessels are used for $\mathrm{H}_{2} \mathrm{SO}_{4}$ and $\mathrm{NH}_{4} \mathrm{NO}_{3}$ aerosols. The annular denuders are placed just upstream of the filter packs to remove any gaseous $\mathrm{HNO}_{3}$ and $\mathrm{NH}_{3}$ that may be produced in the sample stream by the dissociation of $\mathrm{NH}_{4} \mathrm{NO}_{3}$. The diameters of generated particles are chosen to be

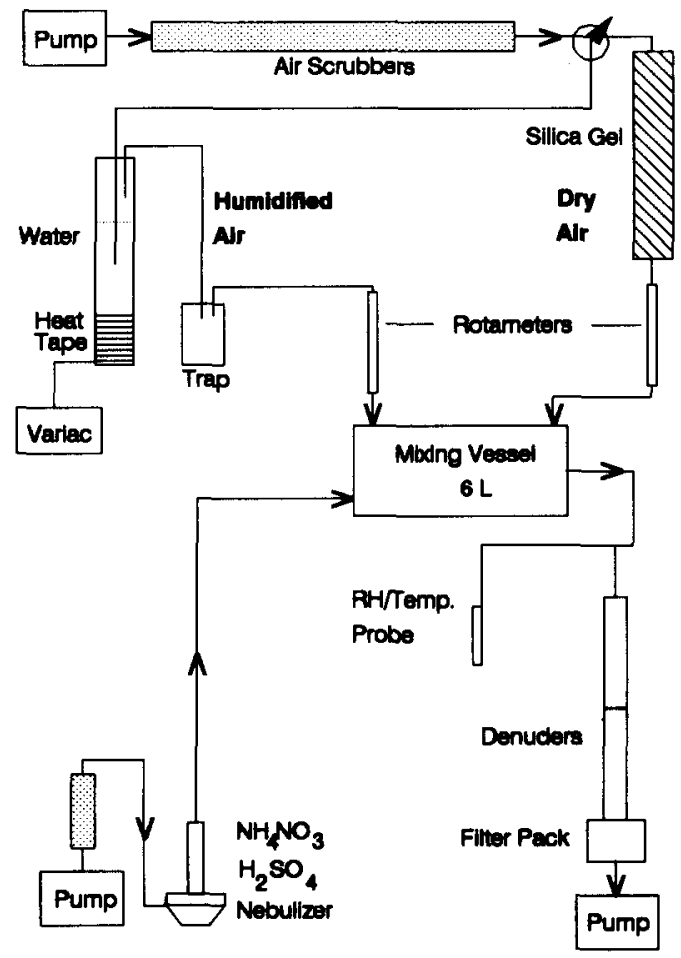

Fig. 2. Schematic of the aerosol generation system. approximately $1 \mu \mathrm{m}$, similar to those observed in previous atmospheric acid aerosol studies (Koutrakis et al., 1989). No impactor is required upstream of the annular denuder series for this system because the generated aerosols have diameters smaller than $2 \mu \mathrm{m}$.

Table 1 summarizes the results of the laboratory tests. The table shows the conditions for each experiment including: the compounds used in each experiment, the experiment numbers, the deposition times for each aerosol, the relative humidity used during the experiment and the sequence of the depositions for experiments 5-9. The table also shows the results of the experiments including: the depositions (in nmoles) of $\mathrm{SO}_{4}^{2-}, \mathrm{NO}_{3}^{-}, \mathrm{H}^{+}$and $\mathrm{NH}_{4}^{+}$measured on the Teflon filter (F1), the ion balance on F1 (the ratio of the cations to anions, which should be equal to one), the deposition of $\mathrm{NO}_{3}^{-}$measured on the $\mathrm{Na}_{2} \mathrm{CO}_{3}$-coated filter (F2), the deposition of $\mathrm{NH}_{4}^{+}$measured on the citric acidcoated filter (F4) and the estimated total hydrogen ion neutralized in units of nanomoles and in percent.

Experiments 1 and 2 involve depositions of $\mathrm{H}_{2} \mathrm{SO}_{4}$ aqueous droplets. As expected, no $\mathrm{NO}_{3}^{-}$was detected on F2; and no $\mathrm{NH}_{4}^{+}$was detected on F4. The ion balance was generally good, but showed a slight contamination of ammonium detected on the Teflon filter. (Since it is very difficult to avoid ammonia contamination during sulfuric-acid particle generation, this unfortunate contamination was not too surprising.) Experiments 3 and 4 involve deposits of ammonium nitrate droplets only. Again, the analysis is good with excellent agreement between the ion balances. Since the annular denuders remove any gaseous $\mathrm{HNO}_{3}$ or $\mathrm{NH}_{3}$ from the sample stream, the $\mathrm{NO}_{3}^{-}$and $\mathrm{NH}_{4}^{+}$detected on $\mathrm{F} 2$ and $\mathrm{F} 4$, respectively, must originate from the dissociation of $\mathrm{NH}_{4} \mathrm{NO}_{3}$ on the Teflon filter by Equation (1). Thus, the results of these two experiments show $5-7 \%$ of the $\mathrm{NH}_{4} \mathrm{NO}_{3}$ dissociated (Equation 1) with the $\mathrm{HNO}_{3}$ detected as $\mathrm{NO}_{3}^{-}$on $\mathrm{F} 2$ and the $\mathrm{NH}_{3}$ detected as $\mathrm{NH}_{4}^{+}$on $\mathrm{F} 4$.

For experiments 5 and 6 , the $\mathrm{NH}_{4} \mathrm{NO}_{3}$ particles are deposited first and the $\mathrm{H}_{2} \mathrm{SO}_{4}$ particles second. In these experiments, the acid on $\mathrm{F} 1$ was neutralized by the $\mathrm{NH}_{4} \mathrm{NO}_{3}$. On the Teflon filter (F1), neutralization occurred if the concentration of $\mathrm{H}^{+}$is lower than twice the concentration of $\mathrm{SO}_{4}^{2-}$ and the concentration of $\mathrm{NH}_{4}^{+}$exceeded the concentration of $\mathrm{NO}_{3}^{-}$. Also, since the concentration of $\mathrm{NO}_{3}^{-}$on $\mathrm{F} 2$ exceeded the concentration of $\mathrm{NH}_{4}^{+}$on $\mathrm{F} 4$, there is evidence of extra nitric acid from the neutralization (Equation 2). The amount of neutralization is the difference between the nitric acid measured on F2 and the ammonia measured on F4 in nanomoles (Equation 5):

$$
\mathrm{H}^{+} \text {(neutralized) }=\mathrm{NO}_{3}^{-}(\mathrm{F} 2)-\mathrm{NH}_{4}^{+}(\mathrm{F} 4) \text {. }
$$

The percentage of neutralization is a comparison of the $\mathrm{H}^{+}$(neutralized) and the $\mathrm{H}^{+}$deposited on the Teflon filter as calculated from the sulfate (Equation 6):

$$
\mathrm{H}^{+}(\% \text { neutralized })=100 \cdot \mathrm{H}^{+}(\text {neutralized }) /
$$

$$
\left(2 \cdot \mathrm{SO}_{4}^{2-}(\mathrm{F} 1)\right) \text {. }
$$


The acid neutralization varies from 37 to $65 \%$ in these experiments. The percentage of neutralization appears to be related to the percentage of relative humidity (r.h.), with greater neutralization taking place at higher r.h.

For experiments 7-9, the $\mathrm{H}_{2} \mathrm{SO}_{4}$ particles were deposited first and $\mathrm{NH}_{4} \mathrm{NO}_{3}$ particles were deposited second. Extensive neutralization of the acid was again evident on the Teflon filter. For F1, the concentration of $\mathrm{H}^{+}$was lower than twice the concentration of $\mathrm{SO}_{4}^{2-}$ and the concentration of $\mathrm{NH}_{4}^{+}$exceeded that of the $\mathrm{NO}_{3}^{-}$. Also, the concentration of $\mathrm{NO}_{3}^{-}$detected on $\mathrm{F}_{2}$ greatly exceeded the low or absent concentration of $\mathrm{NH}_{4}^{+}$on F4. Experiments 7 and 8 show the highest neutralization because of the excess of ammonium nitrate deposited on the Teflon filter.

\section{Discussion of laboratory tests}

The results from these laboratory experiments suggest that the expected volatilization and neutralization reactions occur on the filter medium. These reactions accounted for $32-80 \%$ neutralization of the aerosol acidity observed in these experiments. Therefore, both $\mathrm{Na}_{2} \mathrm{CO}_{3}$ and citric acid-coated filters are needed to measure accurately the acidity lost from the Teflon filter. The degree of neutralization may be related to the relative amounts of $\mathrm{H}_{2} \mathrm{SO}_{4}$ and $\mathrm{NH}_{4} \mathrm{NO}_{3}$ particles, the order of deposition and relative humidity. Further experiments should investigate the particle interaction mechanisms on the filter collection medium. Two possible mechanisms are : (i) particle-to-particle interactions, when particulate ammonium nitrates react with acid sulfate particles; and (ii) gas-to-particle interactions, when ammonia originating from the dissociation of ammonium nitrate (already collected on the filter media) neutralizes the acid particles. At times when the collected ammonium nitrate particles are not in equilibrium with the parent gases, ammonia and nitric acid, dissociation occurs.

\section{FIELD STUDIES}

Table 2 presents the results from acid aerosol measurements conducted as part of the epidemiological study "Acid Aerosol Health Effects in North American Children" (Speizer et al., 1989). According to the study design, yearly monitoring is conducted in eight North American sites. A total of 24 sites are being studied during the 3-year period of 1988-1991. Twenty-fourhour samples are collected using the annular denuder-filter pack system described above. For each site, sampling begins at $8 \mathrm{a} . \mathrm{m}$. and samples are collected every other day (approximately 170 per year). Table 2 summarizes the results from acid aerosol measurements: 3 first-year sites (Dunnville, Ont; Hendersonville, TN; Morehead, KY) and 3 second-year sites (Charlottesville, VA; Oak Ridge, TN; Zanesville, $\mathrm{OH}$ ). These sites, located at eastern and northeastern United States and southeastern Canada, were selected for this analysis because they present higher acid aerosol concentrations compared with the rest of the first-year and second-year sites. Data collected prior to mid-June of 1988 (for the first-year sites) are not included in this analysis because a filter blank problem invalidated the measurements of ammonium on the citric acid filters.

Figures 3-8 present the relationship between $\mathrm{H}^{+}(\mathrm{F} 1)$, the apparent acidity measurement on the Teflon filter, and $\mathrm{H}^{+}$(correction), calculated using Equation (4). These figures reveal that for high $\mathrm{H}^{+}$(F1) concentrations, $\mathrm{H}^{+}$(correction) tends to be near zero.

Table 1. Neutralization of aerosol strong acidity by ammonium nitrate in laboratory experiments. All values are in units of nmoles

\begin{tabular}{|c|c|c|c|c|c|c|c|c|c|}
\hline \multirow{2}{*}{$\begin{array}{l}\text { Aerosol: } \\
\text { Experiment no.: }\end{array}$} & \multicolumn{2}{|c|}{$\mathrm{H}_{2} \mathrm{SO}_{4}$} & \multicolumn{2}{|c|}{$\mathrm{NH}_{4} \mathrm{NO}_{3}$} & \multicolumn{2}{|c|}{$\mathrm{NH}_{4} \mathrm{NO}_{3}+\mathrm{H}_{2} \mathrm{SO}_{4}$} & \multicolumn{3}{|c|}{$\mathrm{H}_{2} \mathrm{SO}_{4}+\mathrm{NH}_{4} \mathrm{NO}_{3}$} \\
\hline & 1 & 2 & 3 & 4 & 5 & 6 & 7 & 8 & 9 \\
\hline \multicolumn{10}{|l|}{ Deposition Time (h) } \\
\hline $\mathrm{H}_{2} \mathrm{SO}_{4}$ & 3.1 & 3.0 & --- & -- & 3.1 & 3.0 & 3.0 & 3.0 & 3.0 \\
\hline $\mathrm{NH}_{4} \mathrm{NO}_{3}$ & - & - & 21.2 & 21.2 & 3.0 & 3.0 & 2.0 & 2.0 & 0.3 \\
\hline $\begin{array}{l}\text { Relative humidity } \\
(\%)\end{array}$ & 75 & 58 & 41 & 41 & 55 & 90 & 53 & 58 & 58 \\
\hline \multicolumn{10}{|l|}{ Teflon filter } \\
\hline $\mathrm{SO}_{4}^{2-}$ & 571 & 866 & - & ..... & 489 & 705 & 792 & 658 & 595 \\
\hline $\mathrm{NO}_{3}^{-}$ & - & -- & 73960 & 63560 & 197 & 144 & 4885 & 3103 & 70 \\
\hline $\mathbf{H}^{+}$ & 1004 & 1822 & - & - & 714 & 125 & 173 & 157 & 740 \\
\hline $\mathrm{NH}_{4}^{+}$ & 54 & 64 & 67800 & 60600 & 339 & 1270 & 6100 & 4062 & 518 \\
\hline $\begin{array}{l}\text { Ion balance on } \\
\text { Teflon filter } \\
\text { (cations/anions) }\end{array}$ & 0.89 & 1.09 & 0.92 & 0.95 & 0.90 & 0.90 & 0.97 & 0.95 & 1.0 \\
\hline $\begin{array}{l}\mathrm{Na}_{2} \mathrm{CO}_{3} \text {-coated } \\
\text { glass filter }\end{array}$ & & & & & & & & & \\
\hline $\begin{array}{l}\mathrm{NO}_{3}^{-} \\
\text {Citric acid-coated }\end{array}$ & - & - & 3924 & 3311 & 732 & 1249 & 1272 & 963 & 386 \\
\hline glass filter $\mathrm{NH}_{4}^{+}$ & - & - & 4476 & 4103 & 370 & 333 & - & 11 & $\ldots$ \\
\hline $\mathrm{H}^{+}$(neutralized) & & & & & 362 & 916 & 1272 & 952 & 386 \\
\hline $\mathrm{H}^{+}(\%$ neutralized $)$ & & & & & 37 & 65 & 80 & 72 & 32 \\
\hline
\end{tabular}


Table 2. Summary of field study results

\begin{tabular}{|c|c|c|c|c|c|c|c|c|c|}
\hline $\begin{array}{l}\text { Site } \\
\text { (no. of samples) }\end{array}$ & $\begin{array}{l}\text { Filter: } \\
\text { Species: }\end{array}$ & $\begin{array}{c}\mathrm{F} 1 \\
\mathrm{NO}_{3}^{-}\end{array}$ & $\underset{\mathrm{SO}_{4}^{2-}}{\mathrm{F} 1}$ & $\begin{array}{c}\mathrm{F} 1 \\
\mathrm{NH}_{4}^{+}\end{array}$ & $\begin{array}{c}\text { F1 } \\
\text { HP* }\end{array}$ & $\begin{array}{c}\mathrm{F}^{2} \\
\mathrm{NO}_{3}^{-}\end{array}$ & $\begin{array}{c}\mathbf{F 4} \\
\mathrm{NH}_{4}^{+}\end{array}$ & HT $†$ & BAL $\ddagger$ \\
\hline Dunnville, Ont & & 11.7 & 66.0 & 117.1 & 26.3 & 14.8 & 15.1 & 33.8 & 1.0 \\
\hline$(93)$ & & $22.6 \|$ & 65.7 & 116.3 & 49.2 & 13.6 & 36.6 & 51.2 & 0.3 \\
\hline Hendersonville, TN & & 1.1 & 60.8 & 83.8 & 30.9 & 8.7 & 11.4 & 36.3 & 1.0 \\
\hline$(151)$ & & 4.9 & 45.5 & 64.5 & 39.0 & 10.0 & 31.1 & 38.1 & 0.3 \\
\hline Morehead, KY & & 3.4 & 65.3 & 93.3 & 36.6 & 6.5 & 8.9 & 39.9 & 1.0 \\
\hline (144) & & 9.3 & 55.3 & 69.6 & 47.6 & 4.9 & 29.2 & 47.1 & 0.2 \\
\hline Charlottesville, VA & & 3.2 & 59.9 & 91.7 & 31.5 & 4.0 & 3.0 & 34.1 & 1.0 \\
\hline (169) & & 10.9 & 49.7 & 57.3 & 35.7 & 3.9 & 13.7 & 36.8 & 0.2 \\
\hline Oak Ridge, TN & & 2.4 & 66.1 & 91.8 & 40.6 & 4.8 & 2.4 & 44.0 & 1.0 \\
\hline (171) & & 6.2 & 47.7 & 57.0 & 47.9 & 4.1 & 6.5 & 48.2 & 0.2 \\
\hline Zanesville, $\mathrm{OH}$ & & 12.5 & 63.3 & 97.7 & 28.5 & 6.7 & 5.6 & 32.3 & 1.0 \\
\hline (171) & & 18.2 & 56.3 & 66.0 & 49.0 & 6.1 & 17.4 & 49.9 & 0.3 \\
\hline Detection limit $\ddagger$ & & 9.8 & 8.8 & 11.8 & 8.0 & 3.2 & 9.6 & & \\
\hline
\end{tabular}

${ }^{*} \mathrm{HP}=\mathrm{H}^{+}$(apparent) and $\mathrm{HT}=\mathrm{H}^{+}$(total).

$+\mathrm{BAL}=$ arithmetic means and standard deviations of the Ion Balances of the F1 filters, where Ion Balance $=\{[\mathrm{HP}]$ $\left.+\left[\mathrm{NH}_{4}^{+}\right]\right\} /\left\{\left[\mathrm{NO}_{3}^{-}\right]+2\left[\mathrm{SO}_{4}^{2-}\right]\right\}$.

If the concentration is less than the detection limit, it is set to $1 / 2$ of the detection limit.

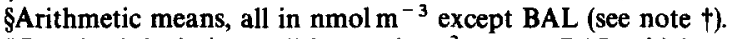

$\|$ Standard deviations, all in $\mathrm{nmol} \mathrm{m}^{-3}$, except BAL which are dimensionless (see note $\dagger$ ).

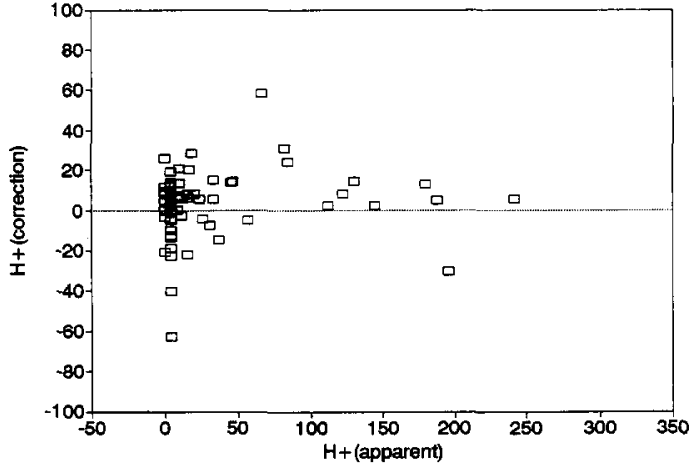

Fig. 3. $\mathrm{H}^{+}$(correction) vs $\mathrm{H}^{+}$(apparent) for data collected in Dunnville, Ont.

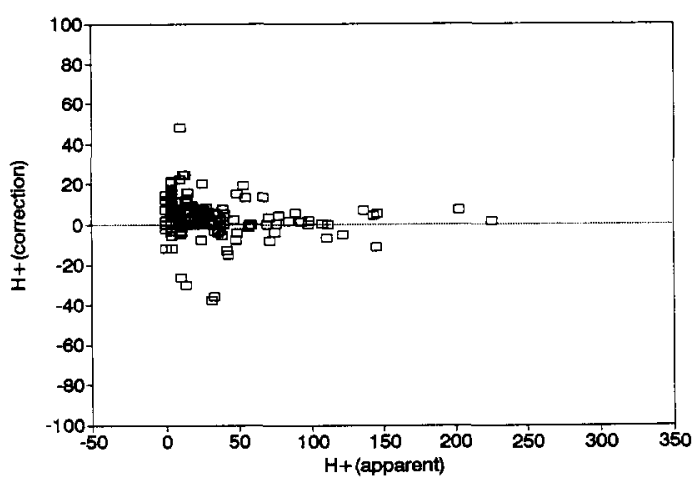

Fig. 4. $\mathrm{H}^{+}$(correction) vs $\mathrm{H}^{+}$(apparent) for data collected in Hendersonville, TN.

In general, for $\mathrm{H}^{+}(\mathrm{F} 1)$ concentrations higher than approximately $40 \mathrm{nmol} \mathrm{m}^{-3}$ (or $2 \mu \mathrm{g} \mathrm{m}^{-3}$ of equivalent $\left.\mathrm{H}_{2} \mathrm{SO}_{4}\right), \mathrm{H}^{+}$(correction) represents only a small percentage of the total aerosol acidity, $\mathrm{H}^{+}$(total), calculated using Equation (3). Therefore, for high-acid

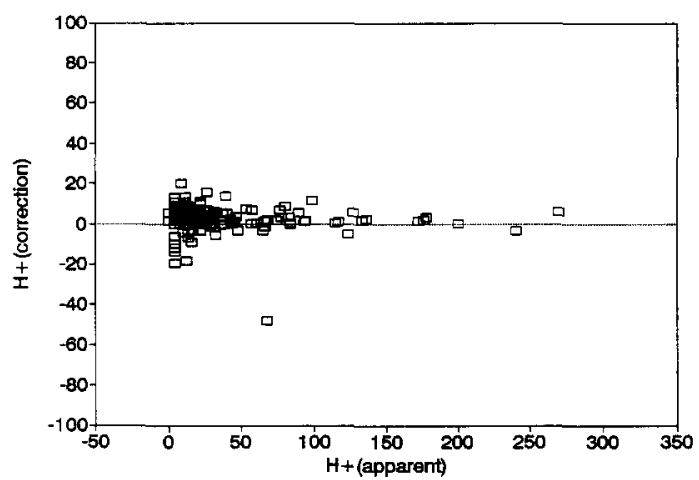

Fig. 5. $\mathrm{H}^{+}$(correction) vs $\mathrm{H}^{+}$(apparent) for data collected in Morehead, $\mathrm{KY}$.

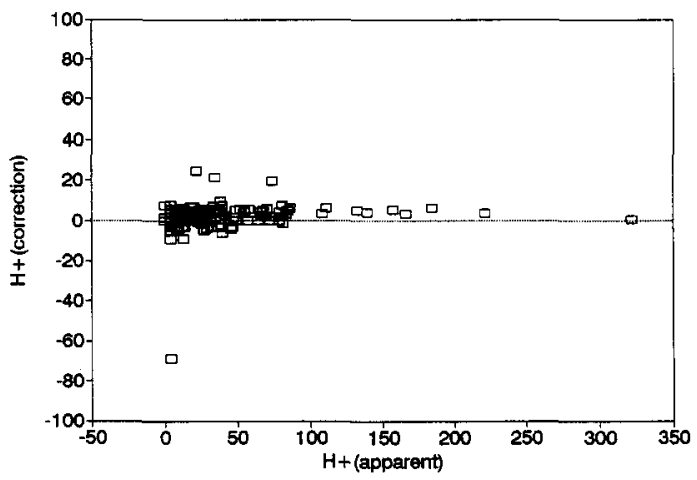

Fig. 6. $\mathrm{H}^{+}$(correction) vs $\mathrm{H}^{+}$(apparent) for data collected in Charlottesville, VA.

aerosol concentrations, the correction factor is negligible. This is expected because for samples corresponding to high acid aerosol concentrations, ammonia concentrations should be low during a great part of the 24-h sampling duration. As a result, 


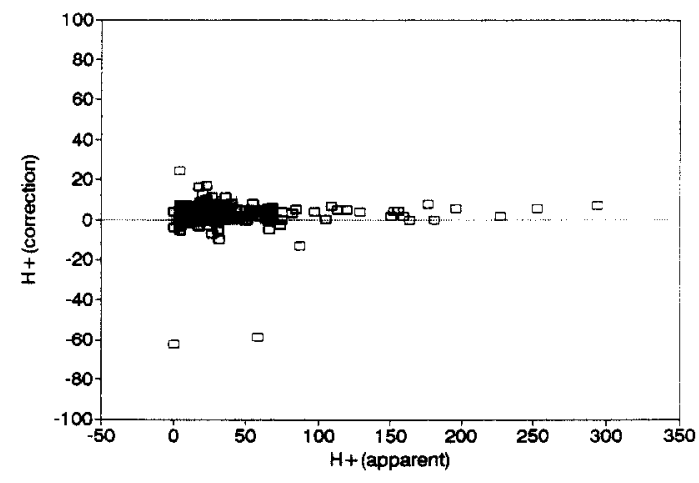

Fig. 7. $\mathrm{H}^{+}$(correction) vs $\mathrm{H}^{+}$(apparent) for data collected in Oak Ridge, $\mathrm{TN}$.

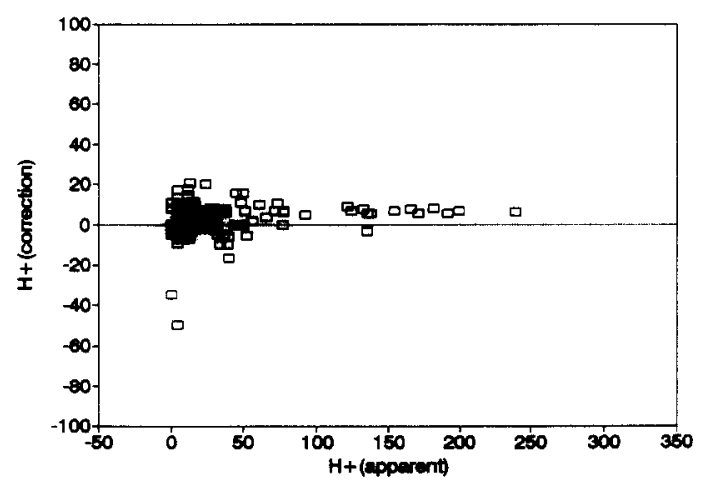

Fig. 8. $\mathrm{H}^{+}$(correction) vs $\mathrm{H}^{+}$(apparent) for data collected in Zanesville, $\mathrm{OH}$.

ammonium nitrate concentrations in these samples are expected to be low and neutralization of acid aerosol sulfate to be minimal.

Table 3 summarizes in more detail the acidity data for the cities in Table 2. The table gives arithmetic means for $\mathrm{H}^{+}$(apparent) (which is the $\mathrm{H}^{+}(\mathrm{F} 1)$ ), the $\mathrm{H}^{+}$(total) found using Equation (3), and the ratio of the $\mathrm{H}^{+}$(total) to the $\mathrm{H}^{+}$(apparent). These means are shown for the valid data collected during the sampling period (approximately 1 year) and for both the high and low acidity seasons. High season includes samples collected between 1 May and 30 September and low season includes samples collected the rest of the year (Koutrakis and Mueller, 1989). The table also gives the percentage differences between the corrected (HT) and uncorrected (HP) averages. Finally, the last two columns of the table give the relative rankings of the cities for the sampling period and the high and low seasons, without and with the correction, respectively. The ranks based on the high-season acidity averages do not change using the correction, which supports the idea that the correction is not important for high acidity concentrations. However, the rankings of these cities for annual and low season averages do change slightly when the correction is made. As this table demonstrates, the rankings switch order for some cities which have similar annual or low season averages. City rankings were changed only in those cases where the averages were very close $(<10 \%$ difference for both apparent and corrected $\left.\mathrm{H}^{+}\right)$. In these cases, the differences in concentration are probably not significantly different in terms of health effects. Therefore, we can conclude that the correction is probably not needed for ambient studies whose goal is to investigate relationships between respiratory health effects and exposure to aerosol acidity. However, corrections may be needed for indoor studies.

As mentioned above, for low $\mathrm{H}^{+}(\mathrm{F} 1)$ concentrations, less than approximately $40 \mathrm{nmol} \mathrm{m}^{-3}$, the correction factor becomes significant and $\mathrm{H}^{+}$(correction) values may be higher than $\mathrm{H}^{+}(\mathrm{F} 1)$. This is expected because these conditions favor ammonium nitrate formation. Interestingly, negative $\mathrm{H}^{+}$(correction) values are depicted in Figs 3-8. Negative correction numbers, down to $\sim 10 \mathrm{nmol} \mathrm{m}^{-3}$, are justifiable by nitrate $(F 2)$ and ammonium $(F 4)$ analysis errors. However, the negative values lower than $\sim 10 \mathrm{nmol} \mathrm{m}^{-3}$ shown by Figs 3-8 suggest that $\mathrm{NH}_{4}^{+}(\mathrm{F} 4)$ concentrations are higher than $\mathrm{NO}_{3}^{-}(\mathrm{F} 2)$. Therefore, our assumption that ammonium (F4) originates only from the dissociation of ammonium nitrate collected on the Teflon filter, (Equation 1), appears to be invalid. However, these high ammonium concentrations may be explained by the following reasons:

(i) If the collection efficiency of the citric acidcoated annular denuder is less than $100 \%$, then part of the ammonia passes through the citric acid-coated denuder and is collected downstream on the citric acid-coated glass-fiber filter (F4); and/or

(ii) If other unstable ammonium salts collected on the Teflon filter dissociate, such as ammonium chloride and/or possibly ammonium salts of organic acids, then $\mathrm{NH}_{4}^{+}(\mathrm{F} 4)$ would originate from dissociation of ammonium nitrate and these other ammonium salts.

The first hypothesis is tested by comparing $\mathrm{NH}_{3}(\mathrm{D} 2)$ and $\mathrm{NH}_{4}^{+}(\mathrm{F} 4)$ concentrations. If the efficiency of the citric acid denuder is less than $100 \%$, negative correction numbers, $\mathrm{H}^{+}$(correction), should correspond to high ammonia concentrations. However, no relationship is found between negative correction numbers and ammonia concentration for any of the six sites, suggesting that this hypothesis is not valid.

For all of the sites, most of the significant negative correction values are observed when aerosol acid is low (when formation of ammonium nitrate and chloride is favored). Although the second hypothesis can not be tested with this collected data because no $\mathrm{Cl}^{-}$ (F2) measurements were made, it may explain the observed phenomenon. The high $\mathrm{NH}_{4}^{+}(\mathrm{F} 4)$ concentrations may be justified by the presence of unstable ammonium salts, other than ammonium nitrate, like those shown in Equations (7) and (8) where HA can be 
Table 3. Summary of field study acidity results

\begin{tabular}{|c|c|c|c|c|c|c|}
\hline & HP* & HT & $\mathbf{H T} / \mathbf{H P} \dagger$ & $\begin{array}{l}\text { Percentage } \\
\text { difference }\end{array}$ & $\begin{array}{c}\text { Rank } \\
\text { HP }\end{array}$ & $\begin{array}{c}\text { Rank } \\
\text { HT }\end{array}$ \\
\hline $\begin{array}{l}\text { Dunnville, Ont } \\
\text { annual mean } \\
\text { high season mean } \dagger \\
\text { low season mean } \dagger\end{array}$ & $\begin{array}{r}26.3 \\
48.3 \\
3.8\end{array}$ & $\begin{array}{l}33.8 \\
57.0 \\
10.0\end{array}$ & $\begin{array}{l}1.3 \\
1.2 \\
2.6\end{array}$ & $\begin{array}{r}28.5 \\
18.0 \\
163.2\end{array}$ & $\begin{array}{l}1 \\
1 \\
1\end{array}$ & $\begin{array}{l}2 \\
1 \\
1\end{array}$ \\
\hline $\begin{array}{l}\text { Hendersonville, TN } \\
\text { annual mean } \\
\text { high season mean } \\
\text { low season mean }\end{array}$ & $\begin{array}{l}30.9 \\
59.6 \\
16.0\end{array}$ & $\begin{array}{l}36.3 \\
62.2 \\
22.8\end{array}$ & $\begin{array}{l}1.2 \\
1.0 \\
1.4\end{array}$ & $\begin{array}{r}17.5 \\
4.4 \\
42.5\end{array}$ & $\begin{array}{l}3 \\
4 \\
4\end{array}$ & $\begin{array}{l}4 \\
4 \\
5\end{array}$ \\
\hline $\begin{array}{l}\text { Morehead, KY } \\
\text { annual mean } \\
\text { high season mean } \\
\text { low season mean }\end{array}$ & $\begin{array}{l}36.6 \\
78.3 \\
16.2\end{array}$ & $\begin{array}{l}39.9 \\
79.6 \\
20.5\end{array}$ & $\begin{array}{l}1.1 \\
1.0 \\
1.3\end{array}$ & $\begin{array}{r}9.0 \\
1.7 \\
26.5\end{array}$ & $\begin{array}{l}5 \\
6 \\
5\end{array}$ & $\begin{array}{l}5 \\
6 \\
4\end{array}$ \\
\hline $\begin{array}{l}\text { Charlottesville, VA } \\
\text { annual mean } \\
\text { high season mean } \\
\text { low season mean }\end{array}$ & $\begin{array}{l}31.5 \\
56.3 \\
15.4\end{array}$ & $\begin{array}{l}34.1 \\
59.1 \\
17.9\end{array}$ & $\begin{array}{l}1.1 \\
1.0 \\
1.2\end{array}$ & $\begin{array}{r}8.3 \\
5.0 \\
16.2\end{array}$ & $\begin{array}{l}4 \\
3 \\
3\end{array}$ & $\begin{array}{l}3 \\
3 \\
2\end{array}$ \\
\hline $\begin{array}{l}\text { Oak Ridge, TN } \\
\text { annual mean } \\
\text { high season mean } \\
\text { low season mean }\end{array}$ & $\begin{array}{l}40.6 \\
65.4 \\
22.2\end{array}$ & $\begin{array}{l}44.0 \\
68.7 \\
25.7\end{array}$ & $\begin{array}{l}1.1 \\
1.1 \\
1.2\end{array}$ & $\begin{array}{r}8.4 \\
5.0 \\
15.8\end{array}$ & $\begin{array}{l}6 \\
5 \\
6\end{array}$ & $\begin{array}{l}6 \\
5 \\
6\end{array}$ \\
\hline $\begin{array}{l}\text { Zanesville, } \mathrm{OH} \\
\text { annual mean } \\
\text { high season mean } \\
\text { low season mean }\end{array}$ & $\begin{array}{l}28.5 \\
53.8 \\
14.4\end{array}$ & $\begin{array}{l}32.3 \\
57.2 \\
18.4\end{array}$ & $\begin{array}{l}1.7 \\
1.1 \\
1.3\end{array}$ & $\begin{array}{r}13.3 \\
6.3 \\
27.8\end{array}$ & $\begin{array}{l}2 \\
2 \\
2\end{array}$ & $\begin{array}{l}1 \\
2 \\
3\end{array}$ \\
\hline
\end{tabular}

${ }^{*} \mathrm{HP}=\mathrm{H}^{+}$(apparent) and $\mathrm{HT}=\mathrm{H}^{+}$(total). All concentrations are arithmetic means in nmol m ${ }^{-3}$.

$\lceil\mathrm{HT} / \mathrm{HP}$ is the ratio of the arithmetic means given in this table. High season is from 1 May to 30 September. Low season is the remainder of the year.

an inorganic or organic acid:

$$
\begin{gathered}
\mathrm{NH}_{4} \mathrm{Cl} \rightarrow \mathrm{NH}_{3}+\mathrm{HCl} \\
\mathrm{NH}_{4} \mathrm{~A} \rightarrow \mathrm{NH}_{3}+\mathrm{HA} .
\end{gathered}
$$

Obviously, such ammonium salts may interact with acid aerosol particles on the Teflon filter, as in the case of ammonium chloride:

$$
\begin{aligned}
& \mathrm{H}_{2} \mathrm{SO}_{4}, \mathrm{NH}_{4} \mathrm{HSO}_{4},\left(\mathrm{NH}_{4}\right)_{3} \mathrm{H}\left(\mathrm{SO}_{4}\right)_{2} \\
& +\mathrm{NH}_{4} \mathrm{Cl}(\mathrm{p}) \rightarrow\left(\mathrm{NH}_{4}\right)_{2} \mathrm{SO}_{4}(\mathrm{p})+\mathrm{HCl}(\mathrm{g}) .
\end{aligned}
$$

An analogous equation may be written for $\mathrm{NH}_{4} \mathrm{~A}$. Then Equation (4) needs to be modified appropriately (Equation 10):

$$
\begin{aligned}
\mathrm{H}^{+}(\text {correction })= & \mathrm{NO}_{3}^{-}(\mathrm{F} 2)+\mathrm{Cl}^{-}(\mathrm{F} 2) \\
& +\mathrm{A}^{-}(\mathrm{F} 2)-\mathrm{NH}_{4}^{+}(\mathrm{F} 4)
\end{aligned}
$$

Clearly, in future measurements, $\mathrm{Cl}^{-}(\mathrm{F} 2)$ and $A^{-}(F 2)$ concentrations need to bo-determined in order to test the second hypothesis and to estimate $\mathrm{H}^{+}$(correction) more precisely. Since $\mathrm{Cl}^{-}(\mathrm{F} 2)$ blank concentrations are high and variable, determining $\mathrm{Cl}^{-}$(F2) is a challenge. Due to the sampling and analysis handling, chloride contamination is inevitable; thus, measurements may be unreliable. Furthermore, $\mathrm{NH}_{4} \mathrm{~A}$ salts need to be identified and examined to determine which of them, if any, need to be included in the correction Equations (4) and (10). Ammonium nitrite is formed when the concentration product $\mathbf{P}$ $=\left[\mathrm{NH}_{3}\right]$ [HONO] exceeds $2.4 \times 10^{9} \mathrm{ppb}^{2}$ at $25^{\circ} \mathrm{C}$ (Brauer et al., 1990); therefore, it is not expected to be present under usual atmospheric conditions. Ammonium formate and acetate salts are also very unstable and are unlikely to be present in ambient air (Grosjean, 1982). Other ammonium salts of organic acids, such as oxalic, malonic, adipic or glutaric, may also be collected on the Teflon filter. Since these organic acids have been identified by previous investigators (Ferek et al., 1983; Grosjean et al., 1982), the sodium carbonate-coated extraction solutions should be analysed for these organic acids. Unfortunately, due to the presence of microorganisms, organic acids decompose during storage and it is not possible to analyse samples collected previously. However, determination of $\mathrm{Cl}^{-}$and $\mathrm{A}^{-}$may be measured in future samples, provided that sampling and analysis protocols are appropriately modified.

Besides the ammonium salts, other salts and alkaline particles may react with acid sulfate particles on the collection media. Equations (11) and (12) show some examples:

$$
\begin{aligned}
& \mathrm{H}_{2} \mathrm{SO}_{4}, \mathrm{NH}_{4} \mathrm{HSO}_{4},\left(\mathrm{NH}_{4}\right)_{3} \mathrm{H}\left(\mathrm{SO}_{4}\right)_{2}(\mathrm{p})+\mathrm{NaCl} \\
& \rightarrow \mathrm{Na}_{2} \mathrm{SO}_{4}(\mathrm{p})+\mathrm{HCl}(\mathrm{g})
\end{aligned}
$$




$$
\begin{aligned}
& \mathrm{H}_{2} \mathrm{SO}_{4}, \mathrm{NH}_{4} \mathrm{HSO}_{4},\left(\mathrm{NH}_{4}\right)_{3} \mathrm{H}\left(\mathrm{SO}_{4}\right)_{2}(\mathrm{p}) \\
& \quad+\mathrm{CaCO}_{3}(\mathrm{p}) \rightarrow \mathrm{CaSO}_{4}(\mathrm{p})+\mathrm{CO}_{2}(\mathrm{~g})+\mathrm{H}_{2} \mathrm{O}(\mathrm{g}) .
\end{aligned}
$$

The reaction with $\mathrm{NaCl}$ can be taken into account if $\mathrm{Cl}^{-}(\mathrm{F} 2)$ is measured; however, the reaction with $\mathrm{CaCO}_{3}$ or other carbonate salts can neutralize acidic sulfates and these acid losses can not be easily determined. Although $\mathrm{CaCO}_{3}$ is mostly associated with coarse particles under usual atmospheric conditions, some of the $\mathrm{CaCO}_{3}$ may be present in the fine-particle mode resulting in underestimation of aerosol strong acidity. Also, it is possible that bounce-off of alkaline coarse particles from the impaction plate could cause neutralization of fine particles collected on the Teflon filter. However, it is not possible to quantify the amount of neutralized acid through this process.

From the analysis and discussion above, it appears that for high-acid aerosol concentrations, acidity losses may be negligible and that correction may not be necessary; whereas, for low concentrations, underestimation of aerosol acidity is possible due to particle interactions. This can be explained because ammonium concentrations are minimal for high acid sulfate concentrations. In contrast, for low acid concentrations, ammonium salts present higher concentrations. Furthermore, negative $\mathrm{H}^{+}$(correction) values, shown in Figs 3-8, may be related to the presence of ammonium salts other than ammonium nitrate. Therefore, the $\mathrm{H}^{+}$(correction) determined using $\mathrm{NO}_{3}^{-}(\mathrm{F} 2)$ and $\mathrm{NH}_{3}^{+}$(F4) represents a minimum correction and negative correction values can be set equal to zero. The determined average and percentage corrections in Table 2 represent minimum corrections. The same table also gives the average concentrations of ammonium, hydrogen, sulfate and nitrate ions.

\section{CONCLUSIONS}

An annular denuder system in conjunction with a newly designed filter pack can be used to examine interactions between acid aerosol sulfates and other particles during sample collection. Both laboratory tests and field studies indicate that particle interactions occur and result in losses of aerosol acidity. Use of the annular denuder filter pack techniques allows for correcting the apparent aerosol strong acidity. For high aerosol acidity concentrations, correction was found to be unimportant; however for low concentrations, correction becomes very important and needs to be taken into account. Negative correction numbers may be related to the presence of ammonium salts other than ammonium nitrate, such as ammonium chloride or ammonium salts of organic acids. Thus, calculations assuming that aerosol strong acidity losses are due exclusively to the presence of ammonium nitrate represent a minimum acidity correction. It may be worthwhile to measure $\mathrm{Cl}^{-}$or other anions collected on the $\mathrm{Na}_{2} \mathrm{CO}_{3}$-coated glass-fiber filter to determine a more accurate correction.

Our results suggest that for concentrations above approximately $40 \mathrm{nmol} \mathrm{m}^{-3}$ of hydrogen ion ( $2 \mu \mathrm{g} \mathrm{m}^{-3}$ of $\mathrm{H}_{2} \mathrm{SO}_{4}$ equivalent) the neutralization percent is minimal. Therefore for our epidemiological studies, neglecting acid correction should not be an important omission since adverse human health effects, if any, are expected to be associated with higher acid exposures. However, for atmospheric chemistry and indoor studies, neutralization effects need to be taken into account.

Acknowledgements - This work was supported by the National Institute of Environmental Health Sciences, grants 1R01 ES0495-01 and ES-07155-01; the Electric Power Research Institute, grant RP1630-59, and Health and Welfare Canada, Health Protection Branch. The authors acknowledge the valuable contributions of the Acid Aerosol Health Effects Study personnel of the engineering, field team, laboratory and data processing groups. The authors thank Michael Brauer for his assistance with the laboratory studies and thorough review. We also thank William E. Wilson for his insightful comments.

\section{REFERENCES}

Brauer M., Koutrakis P., Wolfson J. M. and Spengler J. D. (1989) Evaluation of an annular denuder system under simulated atmospheric conditions. Atmospheric Environment 23, 1981-1986.

Brauer M., Koutrakis P., Keeler G. J. and Spengler J. D. (1990) Indoor and outdoor concentrations of acidic aerosols and gases. J. Air Pollut. Control Assoc. 41, 171-181.

Ferek R. J., Lazrus A. L., Haagenson P. L. and Winchester J. W. (1983) Strong and weak acidity of aerosols collected over the northeastern United States. Envir. Sci. Technol. 17, 315-323.

Grosjean D., Williams E. and Van Neste A. (1982) Measurements of organic acids in the South Coast Air Basin. Final Report for California Resources Board, A5-177-32.

Koutrakis P. and Mueller P. K. (1989) Atmospheric acidity; chemical and physical factors. Presented at the $82 \mathrm{nd}$ Annual Meeting of the Air and Waste Management Association, Anaheim, CA, June 1989.

Koutrakis P., Wolfson J. M., Slater J. L., Brauer M., Spengler J. D. and Stevens R. K. (1988a) Evaluation of an annular denuder/filter pack system to collect acidic aerosols and gases. Envir. Sci. Technol. 22, 1463-1468.

Koutrakis P., Wolfson J. M. and Spengler J. D. (1988b) An improved method for measuring aerosol acidity: results from a nine-month study in St. Louis, MO, and Kingston, TN. Atmospheric Environment 22, 157-163.

Koutrakis P., Wolfson J. M., Spengler J. D., Stern B. and Franklin C. A. (1989) Acidity and growth of atmospheric aerosol sulfates. J. geophys. Res. 94 (D5), 6442-6448.

Koutrakis P., Wolfson J. M., Brauer M. and Spengler J. D. (1990) Design of a glass impactor for an annular denuder/ filter pack system. J. Aerosol Sci. Technol. 12, 607-612.

Possanzini M., Febo A. and Liberti A. (1983) New design of a high-performance denuder for the sampling of atmospheric pollutants. Atmospheric Environment 17, 26052610.

Slater J. L., Koutrakis P., Keeler G. J. and Wolfson J. M. (1989) Determination of aerosol strong acidity losses due to interaction of collected particles: results from laboratory and field studies. Proc. 1989 EPA/AWMA Symp. Measure- 
ment of Toxic and Related Air Pollutants, Raleigh, NC, May 1989.

Speizer F. E. (1989) Studies of acid aerosols in six cities and in a new multi-city investigation: design issues. Envir. Hlth Persp. 79, 61-67.

Stelson A. W. and Seinfeld J. H. (1982) Thermodynamic prediction of the water activity of $\mathrm{NH}_{4} \mathrm{NO}_{3}$ dissociation constant, density and refractive index for the
$\mathrm{NH}_{4} \mathrm{NO}_{3}-\left[\mathrm{NH}_{4}\right]_{2} \mathrm{SO}_{4}-\mathrm{H}_{2} \mathrm{O}$ system at $25^{\circ} \mathrm{C}$. Atmospheric Environment 16, 2507-2514.

Tang I. N. (1980) On the equilibrium partial pressures of nitric acid and ammonia in the atmosphere. Atmospheric Environment 14, 814-828.

Tang I. N., Munkelwitz H. R. and Davis J. G. (1978) Aerosol growth studies-IV. Phase transformation of mixed salt aerosols in a moist atmosphere. J. Aerosol Sci. 9, 505-511. 